\title{
The (Un)Changing Role of Mandarin Chinese in Language Education in Hong Kong
}

\section{Cheung-Shing Samuel Leung}

Department of Speech \& Hearing Sciences, University of Hong Kong, 5/F Prince Philip Dental Hospital, 34 Hospital Road, Hong Kong

\section{Yuen-Fan Lornita Wong}

Department of Chinese \& Bilingual Studies, Hong Kong Polytechnic University, Hung Hom, Hong Kong

With the impending change of status of Hong Kong from a British colony to an integral part of the People's Republic of China (PRC) on 1 July 1997, the future role of Putonghua (Mandarin), which is the national language of the PRC, has been widely debated. In particular, teachers, educationalists and policy-makers are interested to know what will happen within the education system in Hong Kong. Since an overwhelming majority of the population are Southern Chinese in origin, Cantonese is used as a lingua franca in society and as a major medium of instruction at primary level and in the secondary schools which promote mother-tongue teaching. With the expansion of higher education, the use of Cantonese in lectures and seminars in universities is now becoming common. This paper reports on the status and use of the two Chinese varieties, i.e. Cantonese and Putonghua in education in Hong Kong, analyses the increasing economic links and social interaction between Hong Kong and the PRC, and discusses various proposals concerning the (un)changing role of Mandarin in the post-1997 education context.

\section{The Historical Role of Cantonese Chinese and Putonghua in Education in Hong Kong}

Despite the top-down pressure caused by the use of English as a medium of instruction in many higher education institutions in Hong Kong, the majority of primary schools in Hong Kong in the mainstream adopt Cantonese, which is the mother tongue of many of the school children, for classroom instruction. In the Anglo-Chinese secondary schools where teaching is theoretically conducted in English, all Chinese and Chinese-related subjects, i.e. Chinese History, Chinese Literature, together with Chinese Language and Culture - which is a core subject in the sixth form - are taught in Cantonese. In formal written communication at school and in society, Modern Standard Chinese (MSC) which follows the grammatical rules and structure of Putonghua (Mandarin) is used. A general problem faced by many of the school children in Hong Kong is that they are not expected to write Cantonese words which do not have corresponding characters in MSC.

Before the expansion of higher education in Hong Kong in the last decade, English was adopted as the official medium of instruction. At the Chinese University of Hong Kong, although the federal constitution requires Chinese to be used as the principal language of instruction (Chinese University of Hong 
Kong, 1995), lecturers are normally given autonomy to choose an appropriate language (i.e. English, Cantonese or Putonghua) for their lectures.

One of the co-authors' experience as an undergraduate at the Chinese University of Hong Kong was that English was quite often used to teach traditional academic disciplines such as Psychology, Business Administration, Linguistics and, of course, English Literature, whereas Cantonese was the medium of instruction for all Chinese-related subjects. In the 1970s and early 1980s, Putonghua was only offered as an elective subject in the undergraduate programmes at the two universities.

\section{Development of Putonghua Teaching in Hong Kong}

Putonghua education in the Hong Kong school curriculum after the Second World War was known as Guoyin or Guoyu. As a result of the lack of teachers, the subject was no longer offered in primary schools in the late 1950s. Since the numbers of students who registered for the Guoyu examination were decreasing, the subject was deleted in 1965 from the examination syllabus of the Hong Kong Certificate of Education, a public examination taken at the end of secondary education (Form 5), (Ho, 1994).

Taking into consideration the cultural heritage of spoken Cantonese and the syntactic relatedness of written Chinese and Putonghua, the Visiting Panel, invited to review the education system in Hong Kong in the summer of 1981, suggested that Putonghua 'be offered as a publicly financed, extra-curricula' subject in schools to help to eliminate the problems children in Hong Kong were experiencing in written Chinese (Visiting Panel, 1982: 30).

Since the launch of the pilot schemes of Putonghua education in 42 primary schools and 51 secondary schools in September 1981 and July 1984 respectively, feedback from teachers and students has been quite positive and encouraging (Ho, 1994). According to the records of the Education Department, Putonghua education has been offered as an independent and optional subject in about $60 \%$ (515) of the primary schools and 46\% (214) of the secondary schools in Hong Kong during the academic year 1995-96. Owing to the problem of recruiting suitable teachers for this language and because of the heavy demands made by the core curriculum on the timetable, $45 \%$ of the primary and $40 \%$ of the secondary schools can only promote Putonghua learning through extra-curricular activities (Hong Kong Education Department, 1996). In addition to the two different modes of teaching Putonghua which have been identified, $6 \%$ of the secondary schools offer a Putonghua Special Programme outside normal school hours. In conclusion, almost all students in Hong Kong are given an opportunity to learn Putonghua when they reach upper primary or junior secondary level.

Before initiatives by the government to promote Putonghua in schools in Hong Kong were introduced, some well-known private educational institutions such as Jiangsu-Chejiang School and Fujiang Middle School already adopted Putonghua as a medium of instruction for all subjects except in English classes. According to unofficial statistics given by an officer at the Education Department, there are about ten primary and secondary schools using the immersion model to help children to enhance their Putonghua skills. 


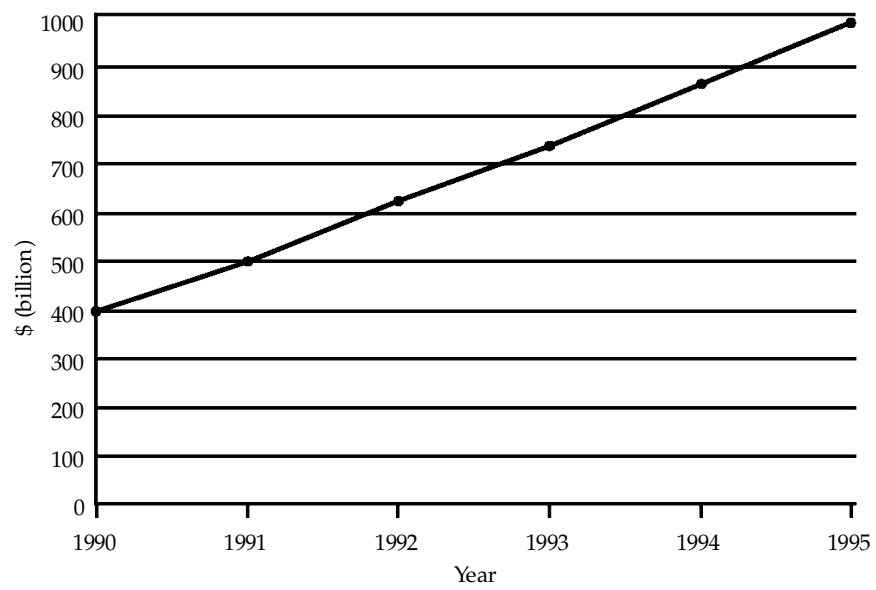

Figure 1 Value of visible trade between Hong Kong and China 1990-1995. Source: Hong Kong Government (1991-1996).

\section{Strength of demand for Putonghua during the political transition}

As a result of the open-door policy of the PRC since 1978 and the enforcement of the new labour and immigration laws in Hong Kong in the last ten years, cross-cultural encounters between the people of Hong Kong and China have increased.

\section{The PRC Chinese Context}

Owing to geographical proximity, the availability of resources and consumer markets, the modernisation programmes and the open-door policy of the PRC, economic exchange between Hong Kong and the PRC has grown. The close economic link is reflected in the value of visible trade between Hong Kong and the PRC which grew from 395 billion dollars in 1990 to 987 billion dollars in 1995. This represents an average increase of 20\% per year in the 1990s (Hong Kong Government, 1991-1996). See Figure 1.

While land and labour in Hong Kong are getting more expensive, many of the Hong Kong owned industries and joint-venture projects have been developed in the Special Economic Zones (SEZs), especially in nearby Guangdong Province (Figure 2).

As a result of these investments, almost three million Chinese nationals have been recruited to work in light industries and hotels which are fully or partially owned by Hong Kong companies in Guangdong (Hong Kong Government, 1996).

Owing to the economic growth and the development of tourism in the PRC, the number of holiday and business trips made by Hong Kong residents to China has grown on average by 10\% each year between 1990 and 1995 (Hong Kong Government, 1991-1996). See Figure 3. 


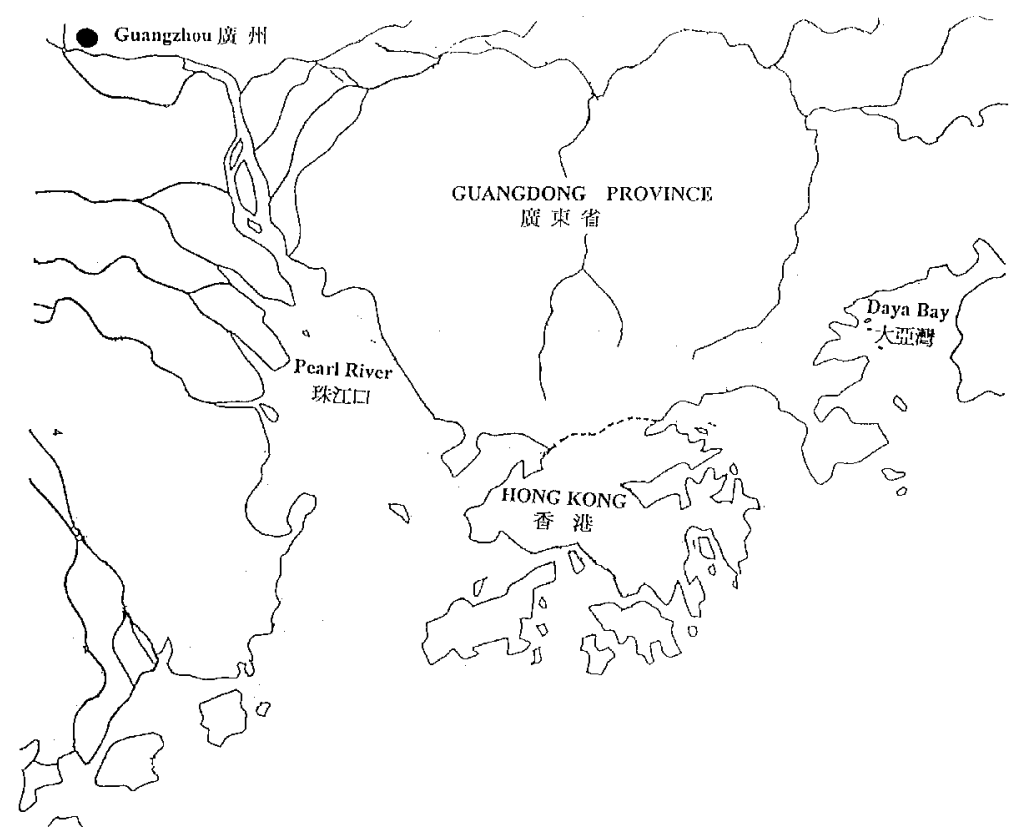

Figure 2 Hong Kong and Guangdong Province.

Source: Wurm et al. (1987)

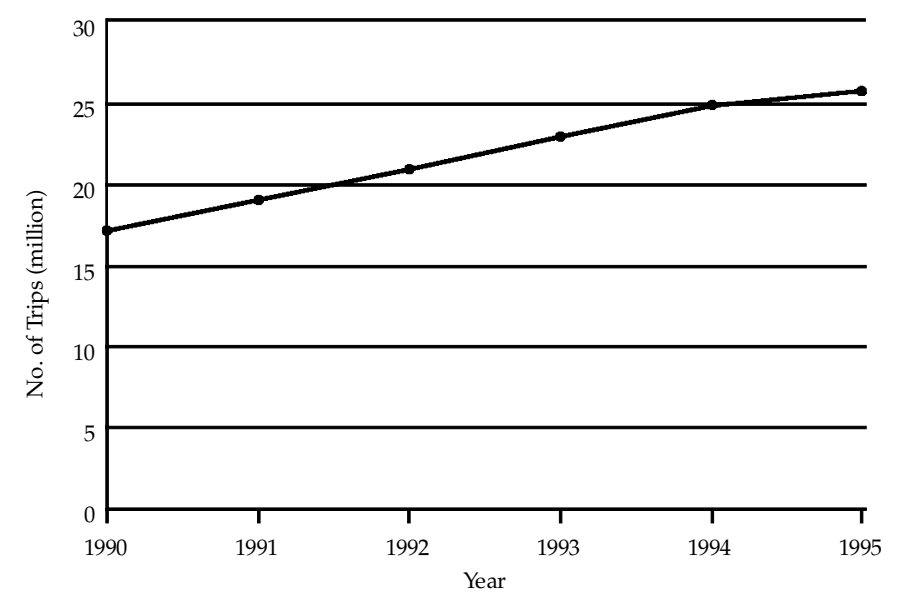

Figure 3 Business/holiday trips made by Hong Kong residents to China. Source: Hong Kong Government (1991-1996).

\section{The Hong Kong Context}

In order to take advantage of the cheap labour supply from the PRC and to facilitate the flow of legal immigrants such as children and wives of cross-border marriages from China into Hong Kong, new laws have been enacted and enforced. With the implementation of the Pilot Scheme from April 1994 onwards, 
a total of 1,000 professionals and specialists from China have been permitted to come to work in Hong Kong every year (Hong Kong Government, 1995). Although official statistics are not available, it is believed that amongst the thousands of foreign skilled workers who have come through the General Importation of Labor Scheme, brought into force in May 1989, and for the construction of the new airport and related projects in Hong Kong (Hong Kong Government, 1990-1996), a considerable number come from mainland China.

With the increase in quotas for legal immigrants from China from 105 to 150 per day since 1 July 1995, an estimated 46,000 immigrants from China have settled in Hong Kong each year. Among the settlers, it has been noted that almost 50\% are children (Hong Kong Government, 1996). The influx of Chinese nationals from the PRC through different agreements affecting immigration legislation implies that the increase in inter-cultural dialogues between local residents and Chinese nationals not only takes place in the work environment but also among children at school.

Because of the shift in the Hong Kong economy towards trade with China (Pease, 1994 in Lin, 1996), and the anticipation of the increasing use of Chinese, including Putonghua, in the civil service in Hong Kong, people in Hong Kong have become quite enthusiastic about learning Putonghua in the 1980s (Tse et al., 1995). The findings of Bacon-Shone \& Bolton's (forthcoming) second sociolinguistic survey of languages in Hong Kong in 1993 also shows an approximate rise of $24 \%$ in the number of people in Hong Kong with a knowledge of Putonghua compared with 1983.

\section{The Future Status and Role of Putonghua as a Language of Education in Hong Kong}

This analysis of the changing economic and social situation confirms that there is a strong and urgent demand for Putonghua in Hong Kong, not only now during the political transition but also in the post-1997 context. In order to prepare effective and competent bilinguals for work in the Hong Kong Special Administrative Region (HKSAR) under the Chinese government, it is clear that Putonghua teaching will have to be restructured and strengthened in the public education sector. Some proposals reflecting the changing status and roles of Putonghua in language education in Hong Kong are summarised as follows:

(1) Putonghua education to be extended to senior secondary level (Forms 4 \& 5) and eventually to become an examination subject in the HKCEE.

(2) Putonghua to be offered as an independent subject from Primary 4 to Secondary 3 , and to be used as the medium of instruction to teach Chinese in some secondary schools on a voluntary basis.

(3) Putonghua to be incorporated into the primary school curriculum as a subject throughout the six years and to be used as the medium of instruction to teach Chinese at secondary level.

(4) Putonghua to be taught as a subject from Primary 4 to 6 and in the first three years in secondary schools (Ho, 1994, Tse et al., 1995).

In order to test the feasibility of the above proposals, the specific initial 
conditions, as suggested by Holmes (1981) in his problem-solving approach to comparative education, are analysed as follows.

\section{Normative patterns}

Many theories and research findings in second language acquisition tend to agree that there is a close relationship between language exposure and acquisition. Immersion programmes adopting the target language as a medium of instruction to help children to develop second language competence have been supported by many educationalists world-wide.

However, the ineffectiveness of the English immersion programme in Anglo-Chinese schools in Hong Kong has long been recognised. From Hong Kong's experience in following the immersion model in Anglo-Chinese secondary schools after the universalisation of the nine-year free compulsory general education in 1978, there have been signs of dissatisfaction about the general academic achievements and the bilingual (English and Chinese) proficiencies of school leavers in Hong Kong (Hong Kong Education Department, 1989; Visiting Panel, 1982; Wong, 1985). If Putonghua is to replace English in the immersion programme, how effective and efficient will education be if it is delivered in a language which is not commonly used at home and in society?

As has been indicated above, Putonghua was not a common or popular subject in schools in the 1950s and 1960s and was only re-introduced into the curriculum in the early 1980s with the official support of the government. The training and supply of Putonghua teachers created difficulties. It is evident that the future expansion of Putonghua education in Hong Kong will depend for its success on the training and supply of competent teachers. In order to prepare teachers for the teaching of Putonghua at school, formal training of Putonghua teachers was incorporated into the pre-service training programme of the three colleges of education in September 1986. Subsequently this training was transferred in September 1994 to the Hong Kong Institute of Education (Hong Kong Education Department, 1996). According to a questionnaire survey conducted between May and July 1991, $87 \%$ out of the 171 serving Putonghua teachers sampled only acquired their Putonghua skills as adults either through in-service training or part-time courses organised by the Adult Education Section of the Hong Kong Education Department, the Hong Kong Institute of Language in Education, universities and other private education institutions (Hong Kong Education Department Institute of Language in Education, 1993). One might ask whether these teachers are fully competent in Putonghua and at ease using it in the classroom.

By modelling on the proficiency distinction established by the State Language Commission in Beijing and with the support of the Hong Kong Bank Language Development Fund, a policy-focused research project aimed at establishing a minimum requirement level of proficiency for Putonghua in Hong Kong was launched in 1991 by a research team at the Institute of Language in Education. Findings of the project (see Figure 4) indicate that the number of the 171 teachers sampled (137 secondary, 34 primary) who were able to reach the Intermediate/ High level of performance in the series of Putonghua competencies was not very satisfactory. Many of the teachers were weak in listening as well as in 


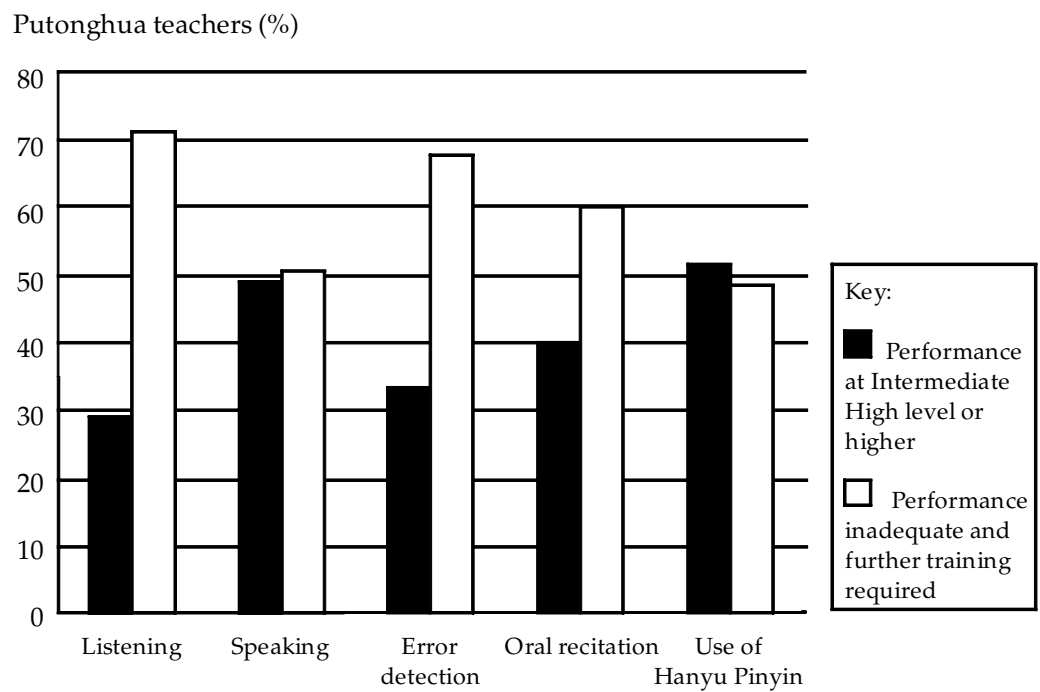

Figure 4 Assessment of competencies of Putonghua teachers in Hong Kong schools. Source: Hong Kong Education Department Institute of Language in Education, 1993.

distinguishing errors in pronunciation and grammar. If the Intermediate/High level is to be considered as the future minimum requirement for Putonghua teachers, the project team suggests that further training will be required for the less competent group - which is in fact the majority (Hong Kong Education Department Institute of Language in Education, 1993).

Under such circumstances, if Putonghua is to be used in the classroom by teachers who are not professionally trained, will there be problems of communication between teachers and students? What could be the consequences in terms of learning, if students cannot follow instructions which are given in a language in which they are not completely competent and which has not been mastered fully by their instructor?

\section{Parental preference}

Since English remains the language of wider communication (LWC) and an instrument for economic and social advancement in the wider world, many Cantonese-speaking parents in Hong Kong still favour English-medium education for their children. The strong objection by parents to the shift from English to the use of Cantonese as a medium of instruction in lower forms at Carmel Secondary School in 1987 shows that it is not easy to gain parental support for changes in the instructional language in classrooms in Hong Kong, where questions of prestige become an element in the decision (Hong Kong Education Commission, 1990).

With reference to Article 136 of the Basic Law, it is stated that 'on the basis of the previous education system, the Government of the Hong Kong Special Administrative Region shall, on its own, formulate policies regarding the 
educational system and its administration, the language of instruction, ... \{and $\}$ the examination system ... ' (The Consultative Committee for the Basic Law of the Hong Kong Special Administrative Region of the People's Republic of China, 1990: 47). This implies that there is a high possibility that the Hong Kong SAR will maintain its authority in education matters after July 1997.

Despite the fact that the Chinese language will be officially recognised as the national language of Hong Kong after the transfer of sovereignty to mainland China, Article 9 of the Basic Law points out that 'English may also be used as an official language by the executive authorities, legislature and judiciary of the Hong Kong Special Administrative Region' (The Consultative Committee for the Basic Law of the Hong Kong Special Administrative Region of the People's Republic of China, 1990: 7).

Since parents know that the educational status quo is likely to remain the same in Hong Kong and that English will continue to play a fairly significant role in the civil service in Hong Kong and in international communication, how many of them will support the use of Putonghua as a medium of instruction?

\section{The primordial and cultural values of Hong Kong Cantonese}

Although the variety of Cantonese spoken in Hong Kong has not been widely accepted in formal, written communication, it is the dominant language of communication amongst the Chinese in Hong Kong. This Cantonese variety not only enables Chinese people in Hong Kong to identify with their group in society, but also reflects the development and the blending of the east-west cultures of Hong Kong. It is expected that people who use the language in their daily interaction will inevitably develop a deep attachment to it (Eastman, 1983). Wong's (1992) survey of the teaching of Chinese to children of Chinese origin in Britain and the USA shows that although Putonghua is seen to be more prestigious than Cantonese, the majority of overseas Cantonese-speaking parents send their children to Cantonese-medium Chinese supplementary schools to learn the Chinese language. Can we extrapolate from such evidence to imply that the use of Putonghua as a medium of instruction at school may not be welcomed by Cantonese-speaking parents in Hong Kong?

\section{Institutional patterns}

Response to the pilot schemes for teaching Putonghua as an independent subject at upper primary and junior secondary levels in 1981-1984 and 1984-1987 respectively were quite satisfactory. Students did indicate an interest in learning Putonghua. There seems to be no problem in maintaining the status quo, teaching Putonghua at the upper primary and junior secondary levels as an independent subject. However, if English remains the second language in the school curriculum, how much time should be allocated to Putonghua and what are the objectives for teaching it at school? The Working Group on Language Proficiency (Hong Kong Education Commission, 1994) suggested that after focusing on mother tongue development in the first three years of primary schooling, a three-year course of English as a foreign language could be phased in in Primary 4. Will there be any adverse effects for the eight-year-olds who will have to learn 
two new languages, namely English and Putonghua, at the same time, in upper primary schools?

The demand for Putonghua appears to be growing at tertiary level. The prospectuses, student handbooks and calendars from 1993 to 1996 of the seven universities in Hong Kong reveal that Putonghua education is now provided at all University Grant Committee-funded (UGC) institutions (Chinese University of Hong Kong, 1995; City University of Hong Kong, 1996; Hong Kong Baptist College, 1994; Hong Kong Polytechnic University, 1996; Hong Kong University of Science and Technology, 1993; Lingnan College, 1995; University of Hong Kong, 1996). From the late 1980s onwards, some of the BA degree programmes, for example, BA in Language and Communication, BA in Translation and Chinese at the Hong Kong Polytechnic University and BEd in Language and Education (Chinese Language and Literature) at the University of Hong Kong have made Putonghua a core subject in the curriculum.

In the past few years, it has been observed that the number of Putonghuaspeaking faculties has increased in universities in Hong Kong. In addition to the use of English for instruction, some of them adopt Putonghua for illustrations in lectures and in tutorials/seminars, especially in subjects related to Chinese language and culture. If a similar staff employment pattern continues, the use of Putonghua as a medium of instruction by Putonghua-speaking academics may become more significant at tertiary level.

In order to ensure that university students achieve an acceptable standard of Putonghua by the time they graduate, Putonghua was a component of a series of exit Chinese language proficiency tests first launched by the Hong Kong Polytechnic University for its graduates in 1995-96. Students graduating in 1996 were encouraged to take the tests on a voluntary basis (Education and Manpower Branch and Civil Service Branch, 1997). Starting from 1997/98, the Putonghua proficiency test will become part of the Graduating Students' Language Proficiency Assessment (GSLPA), which will be implemented for first year degree intakes, on a mandatory basis for language major students and on a voluntary basis for students of other courses (Hong Kong Polytechnic University Faculty of Communication, 1996).

In conclusion, the phenomena identified may eventually exert a certain degree of pressure on the promotion of Putonghua education at school level either as a subject or as a medium of instruction.

\section{The Government's response to the promotion of Putonghua}

Although the official status of Chinese and English has been guaranteed by Article 9 of the Basic Law, the ultimate objective of the language policy formulated by the Government is to establish 'a civil service which is bi-literate (Chinese and English) and tri-lingual (Cantonese, Putonghua and English)' (Hong Kong Education Commission, 1995: 7). As reported in the mass media, some civil servants have been sent by the Hong Kong government to educational institutions in China to learn Putonghua.

In the Governor's 1995 Policy Address, it was announced that a new Putonghua curriculum would be introduced in Primary 1, Secondary 1 and Secondary 4 in September 1998, and it is expected to include Putonghua in the 
Hong Kong Certificate of Education Examination as an independent subject in the year 2000. In order to achieve the target, it has been decided by the Government that an annual provision of $\$ 10$ million be channelled into schools for the improvement and expansion of Putonghua education. The Language Fund created by the Government in May 1994 has also financed projects related to Putonghua enhancement (Hong Kong Education Commission, 1995).

\section{Conclusions and Recommendations}

The analysis of the specific initial conditions above indicates that the teaching of Putonghua as a subject will meet no objection from the community for political or economic reasons. Since targets for Putonghua education at school have been set by the Government, the teaching of Putonghua is likely to be extended to all levels of primary and secondary schools by the year 2000 .

Since research evidence has indicated that the performance of the majority of the serving teachers sampled in the Putonghua proficiency tests conducted in 1991 had not reached the minimum level of competencies (Hong Kong Education Department Institute of Language in Education, 1993), teaching will be inefficient and ineffective if Putonghua is used as a medium of instruction for all subjects or for the Chinese language subject only. Even though the inadequacies of the Hong Kong-trained Putonghua teachers can be compensated for by recruiting competent Putonghua speaking teachers from Mainland China, teaching and communication between teachers and students can be difficult if teachers are not familiar with the local language and Hong Kong culture.

In terms of parental preference, the experience of teaching Chinese language overseas (Wong, 1992) together with our knowledge of the fact that cultural and emotional values are embedded in all languages including spoken Cantonese lead us to conclude that parents might be reluctant to support the complete omission of Cantonese from the school curriculum.

Given that the Hong Kong Education Commission (1994) and many educationalists advocate that mother tongue education should be given priority in the first few years of schooling, Cantonese should continue to be used as the major medium of instruction at primary level and to be extended to junior secondary level if there is a need. Similar to the effort made to identify the $30 \%$ of the student cohort who may benefit from English-medium education (Hong Kong Education Department, 1989), research ought to be conducted to find out the appropriate age group and the percentage of students who will benefit more from Putonghua-medium education.

Under the colonial administration, Hong Kong never had any clear-cut policies on language in education, especially concerning the medium of instruction at school. For the two decades up to the retreat of the British government, educational reforms have been piecemeal and hasty. The increasing use of Putonghua in the Hong Kong economy after China opened its doors in the late 1970s has made the formulation and the implementation of policies concerning the language of education more complicated. Therefore, more studies and projects related to language policies in education should be encouraged so as to develop strategies to enhance the tri-lingual proficiencies (Cantonese, 
Putonghua and English) of students in the Hong Kong Special Administration Region.

\section{Acknowledgments}

The authors of the paper would like to express their gratitude to their research assistants, Miss Hidy Leung, Mr. Alexander Ha and Miss Pauline Teng for their help. The co-author Lornita Wong would like to dedicate this paper to the late Professor Brian Holmes, who inspired her to education and research.

\section{References}

Bacon-Shone, J. and Bolton, K. (forthcoming) Charting multilingualism: Language censuses and language surveys in Hong Kong. In M.C. Pennington (ed.) Language in Hong Kong at Century's End. Hong Kong: University of Hong Kong Press.

Chinese University of Hong Kong (1995) The Chinese University of Hong Kong Student Handbook 1995-96. Hong Kong: CUHK.

City University of Hong Kong (1996) Prospectus for Bachelor's Degree Courses (1996 Entry). Hong Kong: City University of Hong Kong.

Consultative Committee for the Basic Law of the Hong Kong Special Administrative Region of the People's Republic of China (1990) The Basic Law of the Hong Kong Special Administrative Region of the People's Republic of China. Hong Kong: The Consultative Committee for the Basic Law of the Hong Kong Special Administrative Region of the People's Republic of China.

Eastman, C. (1983) Language Planning: An Introduction. San Francisco: Chandler \& Sharp. Education and Manpower Branch and Civil Service Branch (1997) Language Training Courses Organised for University Students (Press release). Hong Kong: Hong Kong Government Information Services.

Ho, K.C. (1994) Tansuo Xianggang putonghua jiaoxue de luxiang (An investigation into the development of Putonghua education in Hong Kong). In Hong Kong Chinese Language Education Association (ed.) Yuwen Jiaoxue Mianmianguan (A Multiple Perspective on Language Education). Hong Kong: Hong Kong Cultural Education Press.

Holmes, B. (1981) Comparative Education: Some Considerations of Method. London: George Allen \& Unwin.

Hong Kong Baptist College (1994) Hong Kong Baptist College JUPAS 1994-95 Undergraduate Prospectus. Hong Kong: Hong Kong Baptist College.

Hong Kong Education Commission (1990) Education Commission Report No. 4. Hong Kong: Government Printer.

Hong Kong Education Commission (1994) Report of the Working Group on Language Proficiency. Hong Kong: Government Printer.

Hong Kong Education Commission (1995) Education Commission Report No. 6 Part 1 (Main Report). Hong Kong: Government Printer.

Hong Kong Education Department (1989) Report of the Working Group Set up to Review Language Improvement Measures. Hong Kong: Government Printer.

Hong Kong Education Department Institute of Language in Education (1993) Research Report on the Basic Competencies of Putonghua Teachers, Programmes of Training of Putonghua Teachers and Curriculum Development. Hong Kong: Government Printer.

Hong Kong Education Department (1996) Putonghua Teaching (a facsimile document). Hong Kong: Education Department.

Hong Kong Government (1990) Hong Kong 1990. Hong Kong: Government Printer. Hong Kong Government (1991) Hong Kong 1991. Hong Kong: Government Printer. Hong Kong Government (1992) Hong Kong 1992. Hong Kong: Government Printer. Hong Kong Government (1993) Hong Kong 1993. Hong Kong: Government Printer. Hong Kong Government (1994) Hong Kong 1994. Hong Kong: Government Printer. Hong Kong Government (1995) Hong Kong 1995. Hong Kong: Government Printer. Hong Kong Government (1996) Hong Kong 1996. Hong Kong: Government Printer. 
Hong Kong Polytechnic University (1996) Prospectus for Undergraduate Full-time Studies 96/97. Hong Kong: HKPU.

Hong Kong University of Science \& Technology (1993) Hong Kong University of Science E Technology: Prospectus for Entry in 1993-94. Hong Kong : HKUST.

Lin, A.M.Y. (1996) Bilingualism or linguistic segregation? Symbolic domination, resistance and code switching in Hong Kong schools. Linguistics and Education 8, 49-84.

Lingnan College (1995) Lingnan College Hong Kong Calendar 1995-96. Hong Kong: Lingnan College.

Pease, R.M. (1994) Mandarin may become Asia's language of commerce. The Asian Wall Street Journal Weekly (19 September 1994), p. 12.

Tse, S.K., Chan, W.S., Ho, W.K., Law, N., Lee, T., Shek, C., Wong, C. and Yu, F.Y. (1995) Chinese Language Education for the 21st Century: A Hong Kong Perspective (Education Papers 21). Hong Kong: Faculty of Education, The University of Hong Kong.

University of Hong Kong (1995) Calendar 1995-1996. Hong Kong: HKU.

Visiting Panel (1982) A Perspective on Education in Hong Kong. Hong Kong: Government Printer.

Wong, L. (1992) Education of Chinese Children in Britain and the USA. Clevedon: Multilingual Matters.

Wong, Y-F.L (1985) Democratization of the nine-year general education in Hong Kong, with special reference to the language policies in education (unpublished MA Dissertation). London: Institute of Education, University of London.

Wurm, S.A., Tsou, B., Bradley, D. and Li, R. (1987) Language Atlas of China. Hong Kong: Longman. 